\title{
Archiving Challenges of Scholarly Electronic Journals: How Do Publishers Manage Them?
}

By

\author{
Golnessa Galyani Moghaddam (Ph.D) ${ }^{1}$
}

\begin{abstract}
:
With the growing number of scholarly journals in electronic format, long-term preservation of scholarly electronic journals has become one of the most important issues in digital libraries. Accessibility of scholarly journals on the Internet and electronic publishing in general is causing a shift in the responsibility for archiving journals from libraries to agreements between libraries and publishers. The author focuses on some of the important issues surrounding preservation of digital resources, especially scholarly electronic journals and presents a study on the archiving policies of the following publishers: Elsevier, Springer, Taylor \& Francis, Cambridge University Press, Oxford University Press, and IEEE.
\end{abstract}

Keywords: Electronic Archiving, Electronic Journals, Publishers, Digital Preservation

\section{Introduction}

Scholarly electronic journals have become the largest and fastest growing segment of digital collections for most libraries. Many issues and concerns for managing electronic journals relate to preserving and providing continued access to them. In this paper the author deals with issues concerning archiving of scholarly electronic journals. Following the discussion of challenges and issues, the author presents the results of a study on the archiving policies of six major publishers.

\footnotetext{
${ }^{1}$ Moghaddam is a Member of the Faculty, Department of Library and Information Science, Shahed University, Tehran, Iran; e-mail: g_galyani@yahoo.com
} 


\section{Archiving Challenges}

Electronic archiving of scholarly journals is an important issue for libraries. This issue cannot be neglected any more because the usage of electronic journals has increased significantly in recent years [1,2]. Electronic journals have many advantages over print journals. Online access allows for easier searching and retrieval of a topic. Electronic journals can be accessed anywhere (given proper equipment and software), and they have the ability to link to other people and resources beyond locations or "place."

With the greater capability of the digital medium, however, the content of digital files may be lost to future scholars not just because the physical item deteriorates, but because the information cannot be extracted and interpreted correctly. A scholarly journal on the printed page can be viewed and read without any special equipment as long as one knows the language in which it is written. Digital scholarly journals, however, cannot be viewed with special equipment, such as a computer, an Internet connection, and the required software. Richard Poynder explains the differences between print and digital media as follows:

Unlike paper or microfilm where the meaning is transparently inscribed on the surface of the medium - digital documents are opaque bit streams only understandable to humans when interpreted by a machine. The hardware and software to do this interpretation, however, is constantly superseded. There have, for instance, been more than 200 digital storage formats alone deployed since the 1960s, with none lasting more than 10 years [3].

With the machine dependency, archiving of electronic journals is more complicated than archiving print journals. The life expectancy of digital media is another issue of concern. The short lifecycle of digital media is a threat for digital archiving because digital media become obsolete much faster than print media. The format of the digital resources can be damaged or lost and may no longer be intact, retrievable, understandable, or displayable. The technology used to store the publication is likely to become obsolete even before that happens [4]. Therefore, continued access to archived resources is a big issue in digital archiving, while "access" was not a big issue to traditional archiving. 
Developments in information technology have also changed the traditional system of publishing, distributing, and even the use of scholarly journals. The initial communication for publishing a paper is so quick now, especially with the help of e-mail. An accepted manuscript can be accessed online before the date of publication. The distribution cost of journals has also decreased in the digital environment [5]. Even the patterns of use of scholarly journals are changing in the digital environment $[6,7]$.

Moreover, information technology has caused substantial changes in the traditional roles of libraries and publishers [8]. One of the major changes is a shift in responsibility of archiving from libraries to publishers in an electronic environment. Historically, archiving records and documents has long been the responsibility of librarians, and publishers largely shied away from this role. Several libraries hold many research journals in print from their first volumes. Few publishers have complete journal collections archived for posterity.

Regarding legal issues, the Internet and electronic journals make the task of illegal copying and distribution easier. Equally, the Internet and electronic journals make the task of policing a very difficult one. While copyright permits only fair use and prohibits all distribution whether for profit or non-profit, enforcing copyright in the electronic environment is a complex task for publishers, institutions, and governments. Internet and electronic journals have created new paradigms for archiving journals, resulting in controversial debates, especially in light of new technological complexities [9].

In the shift from print to electronic formats, the story of ownership is also changing. One reason is the nature of licensing under which these journals are now distributed. When publishers arrange for scholarly journals online through licensing agreements, libraries do not have local possession of a copy as they did with print nor do they own the publications. As a consequence, the archiving of printed publications implicitly offered by library collections no longer exists for electronic journals. The license is not something for ownership; it is only an agreement for use. Users access content stored on remote systems controlled by publishers, and the economies of scale in electronic publishing are driving control of more and more journals into fewer and fewer 
hands. If a publisher fails to maintain its archive for any reason, there would not access to those resources.

One of the problems with archiving electronic journals is the mergers of publishers. Several significant mergers have occurred in recent years. For example, in 2003 Academic Press merged with Elsevier, and its journals became available through ScienceDirect. What happened to back issues of these journals? This is a key question that publishers must consider. For Academic Press, all of its titles were migrated from their platform to ScienceDirect. Academic Press sent their journals to the KB (Koninklijke Bibliotheek or the National Library of the Netherlands) at the time they were added to Science-Direct. Now, all of the Academic Press titles and their backfiles are at the KB.

In migrating from print to the electronic environment, standards play an important role in electronic archiving; however, there is a debate over the success of standards for computers. In 1999 David Bearman pointed out that "no computer technical standards have yet shown any likelihood of lasting forever." Of course, it is rationale [sic] to adhere to standards [10]. According to the National Library of Australia's initiative for preserving digital resources (PADI), "resources which are encoded using open standards have a greater chance of remaining accessible after an extended period than resources encoded with proprietary standards" [11]. At present, technical issues and challenges related to digital preservation include a lack of practical implementations of preservation standards and a lack of technical knowledge, in general, of what information is required to support the digital preservation process within the institutions [12].

\section{Other Archiving Considerations}

"Selection" is another important issue in electronic archiving. The huge quantity of information being produced digitally, its variable quality, and the resource constraints on those taking responsibility to preserve long-term access make selectivity inevitable for archiving. Traditionally, lack of selection for preservation may not necessarily mean that the item will be lost, but in the digital environment non-selection for preservation will almost certainly mean loss of the item. Although not all resources can or need to be preserved forever, some will not need to be preserved at all, others will need to be 
preserved only for a defined period of time, and a relatively small sub-set will need to be preserved indefinitely.

In traditional archiving, some level of redundancy with multiple copies was inevitable in different repositories, but the story is different in the electronic environment. Some authors, such as Dale Flecker (2001), believed that there was large-scale redundancy in the storage of journals in the print era, as many different institutions collected the same titles. Theoretically, in a digital environment, a single institution can provide worldwide access and accept preservation responsibility, although there is a debate whether a level of redundancy should exist in the digital environment [13].

The other important concern in electronic archiving is legal issues, such as copyright and intellectual property rights. How will copyright and intellectual property rights be managed in archiving electronic journals? We know that copyright law originated long before there was a thought of the World Wide Web. Copyright seems to be established well for traditional archiving but not for electronic materials. The copyright and intellectual property rights issues for digital materials are much more complex and significant than for traditional media. If these issues are not addressed adequately, preservation will be curtailed.

Adrienne Muir believes that both publishers and librarians perceive threats in the digital environment. She observed that some authors are quite happy for their material to be widely accessible, while some publishers do feel threatened. The ease of distribution and duplication offered by new technologies raises commercial concerns and has driven publishers to seek control of content through legal and technical tools, such as licensing and digital rights management. But libraries are involved in providing access to information, and librarians have concerns that new approaches threaten legitimate access to the detriment of the public good [14].

Although making changes in law or licensing practice is difficult, rights holders and libraries have to understand and cooperate with each other to progress. There are many stakeholders who may have an interest in archiving electronic journals. Mary Feeney describes in detail the stakeholders as authors, publishers, libraries, archive centers, distributors, networked information service providers, IT suppliers, legal 
depositories, consortia, universities, and research funders. Feeney also suggests considering the relationship of the stakeholder to the digital material archiving [15].

\section{Cooperation and Communication}

Electronic archiving is also expensive and creates new levels of responsibility for publishers and for libraries, involving functions similar to data storage. Electronic archiving requires considerable costs for infrastructure and maintenance. If the publishers can develop an institutional model and legal framework to guarantee perpetual access to the subscribed journals for every subscriber, libraries may need not archives. However, the geo-political factors, the frequent corporate changes at publishing organizations in terms of mergers, and the changes in the structure and ownership of journal become compelling factors for the library to think of independent local archiving. Apart from the high cost of infrastructure and maintenance, archiving will be a substantially repetitive cost for every library in a community. Moreover, it can be a cooperative task and costsharing activity among the libraries in a community who can assign the responsibility to one of its members. Shared responsibility, however, would not be enough to secure archiving of electronic journals.

Libraries and archives already realize the importance of archiving and preserving continued access to digital materials, and many institutions have begun to take initial steps to meet their responsibility effectively. The new concerns of electronic archiving have led to a series of meetings over the past few years among publishers, librarians, and technologists and sponsored by a variety of organizations. A number of the academic librarians, university administrators from the United States, and others who participated in a meeting to discuss electronic journal preservation at the Andrew W. Mellon Foundation offices in New York on September 13, 2005, suggested four key essential actions regarding archiving as follows:

First, research and academic libraries and associated academic institutions must recognize that preservation of electronic journals is a kind of insurance, and is not in and of itself a form of access. Second, in order to address these risk factors and provide insurance against loss, qualified preservation archives would provide a minimal set of well-defined services. Third, libraries must invest in a qualified archiving solution. Finally, research and academic libraries and associated 
academic institutions must effectively demand archival deposit by publishers as a condition of licensing electronic journals [16].

The participants agreed that these actions may not be easy, but in a scholarly environment that is increasingly dependent on information in digital form, preservation of electronic journals is necessary and urgent. They pointed out that universities, colleges, and their libraries have recently been working together to help scholars manage their copyrights and to craft alternatives to high priced forms of scholarly publishing. It is now equally important that research and academic libraries work with scholars - and their publishers - to sustain future research and teaching by establishing trusted archives in which the published scholarly record in electronic form can persist outside of the exclusive control of publishers, and in the control of entities that value long-term persistence [17].

\section{Literature Review}

There are few researches which were undertaken on archiving issues till date. UNISON (University Librarians in the State of New South Wales) commissioned a study of the issues associated with the archiving of electronic scholarly information as a means of developing strategic options applicable in the Australian higher education context in 1998. This study found the following interesting results:

1. Archiving of journals in the digital age is far more complex than the preservation of print collections and likely to become increasingly so. Although often presented as primarily a technological issue, its more intractable dimensions are economic, organisational, social and legal.

2. Scholarly publishing, with all its economic perversities, is a fertile ground for mistrust in relationships between publishers, distributors and university librarians. Solutions to long term archiving of journal collections which leave university librarians in an unequal negotiating position vis-à-vis publishers or which run the risk of entrenching monopoly power are unlikely to deserve, or to gain, library support. 
3. The shift to electronic publication will be rapid, however, fundamental changes in the nature of scholarly communication will be much slower. This may justify the search for archiving solutions that are expedient in the short term.

4. The legal issues relating to copyright and ownership of information are, if anything, more challenging than the technical ones. This stems in large part from existing copyright laws which, whilst under review, have not yet been amended to take account of a digital environment.

5. The business case for long term archiving is inextricably bound up with the economics of electronic journal publishing. The dominant feature of the publishing industry is that of high fixed costs and low marginal costs of use, however, this business model may not readily translate into any archiving service paradigm.

6. Comparison with print preservation costs can be misleading since capital costs of physical infrastructure have not been generally factored in.

7. The cost structuring of archiving and retrieval in the long term will be realigned to reflect users' search strategies and the way in which they use information. Accurate pricing for long term archiving, whether built into subscriptions/licence fees or on a transactional cost basis, will need to be supported by good usage data.

8. Most major publishers probably will have an interest in maintaining access over time and will store and migrate the information themselves until such time as the serial data is no longer of interest or economic value [18].

A study carried out in UK, looked at non-national museums, libraries and archives in two English regions - the North East and West Midlands - to discover how well prepared they are to deal with the problems of keeping digital material in the long term. The results show that there is a significant commitment to digitisation, with over 80 digitisation projects currently in place. In addition, the organisations surveyed expressed a need for help and advice on a range of digital preservation issues. However, the bulk of activity covered by the survey has been the digitisation of existing collections rather than in tackling the issues raised by born-digital material. The results suggested that long-term management of digital material needs to be more firmly embedded in corporate thinking 
and planning and awareness raising on the whole issue of digital preservation is needed [19].

Catherine Ayre and Adrienne Muir have discussed on the issues of copyright and intellectual property right in their paper. Ayre and Muir (2004) explored whether digital preservation actions would be legal under current provisions relating to copyright, database rights, moral rights and circumvention of rights management technology in the UK. They found that the only type of copying that may be legal under the preservation exception in UK law is the first act of media refreshment or migration to a new format. Although other preservation actions require multiple acts of copying of the same material, it could be argued that these too fall within at least the spirit of the law. A conclusion from the Ayer and Muir (2004) report is that progress in addressing the legal issues potentially inhibiting preservation of digital information can only be made by raising awareness of preservation issues among the interested parties, reassuring rights holders that librarians are law-abiding and that preserving heritage is a public good. [20].

The fragility of electronic resources, as an important issue in electronic archiving, is reported in the literature. For example, in October 2003, Science published the results of a survey which found that three months after publication, 3.8\% of the internet references in three high-impact medical journals were inactive; at 15 months this percentage had risen to $10 \%$; and it rose again to $13 \%$ at 27 months after publication [21]. Similarly, a 2005 study published in The Serials Librarian showed that three years after publication, half of the internet references in three top communications journals did not link to active content [22]. The fragility of electronic resources has significant implications for scholars who are troubled by the possibility of gaps in the scholarly record and the impact that these may have upon their ability to generate new scholarship which builds upon the work of today's researchers. The concerns for libraries may be even more striking [23].

Literature reviews also show that with more accessibility of electronic scholarly resources, concern about the long-term preservation and future accessibility of the electronic portion of the scholarly record has grown. One recent survey found that $83 \%$ 
of academic staff surveyed believe it is 'very important' to preserve electronic scholarly resources for future use [24].

In 2003-04, libraries surveyed by the Association of Research Libraries (ARL) expended total institutional resources of US\$301,699,645 to license electronic materials. On average, $31 \%$ of total library material expenditures are devoted to electronic resources [25]. If one extends this expenditure trend beyond the membership of the ARL, the total investment which libraries across the higher education community are making in licensing access to electronic resources is truly noteworthy and suggests that efforts to protect and preserve these resources would be a wise investment [26].

At last, a dissertation carried our in UK focuses upon the challenges and problems that libraries face relating to the accessing and archiving of electronic journals. By looking at publishers and other stakeholders, it is argued that although technically the archiving process is feasible, poor relations between libraries and publishers make this difficult to achieve. The author concluded that it is hard to reach a consensus on how the process should be carried out and the lack of developed standards exacerbates this problem. Economic, legal, business and organisational models must be considered before the archiving of electronic journals can be facilitated effectively. The dissertation looks at how these can be achieved and highlights the importance of further detailed research in this field [27].

\section{Study of Archiving Policies among Publishers}

Publishers of scholarly electronic journals are one of the important stakeholders of electronic archiving. They often follow their own policies for archiving of electronic journals which are being published and owned by them. In order to have a better picture of their views, the author studied the policies of the six leading publishers. Publishers of scholarly electronic journals are categorized into two main groups: for-profit/commercial publishers, not-for-profit/universities presses and society publishers. It was difficult to distinguish between for-profit and not-for-profit publishers; it must be noted, therefore, for the purposes of this study, that academic presses were grouped with the not-for-profit publishers. Fifteen top for-profit and fifteen top not-for-profit publishers were identified and ranked by their number of electronic journals in 2007 (See Table 1 and Table 2). 


\begin{tabular}{|c|l|c|c|}
\hline \multirow{2}{*}{ Rank } & \multicolumn{1}{|c|}{ For-Profit Publishers } & \multicolumn{2}{c|}{ Number of E-Journals } \\
\cline { 3 - 5 } & & In 2003 & In 2007 \\
\hline 1 & Elsevier (Includes Academic Press) & 1,349 & 2,220 \\
\hline 2 & Springer - Verlag (Includes Kluwer) & 436 & 1,616 \\
\hline 3 & Taylor \& Francis Group & 740 & 1,321 \\
\hline 4 & Blackwell Publishing & 577 & 850 \\
\hline 5 & John Wiley \& Sons, Inc & 309 & 464 \\
\hline 6 & Sage Publications & 317 & 460 \\
\hline 7 & Lippincott Williams and Wilkins & 230 & 296 \\
\hline 8 & Haworth Press & 193 & 210 \\
\hline 9 & MCB University Press (Emerald) & 138 & 175 \\
\hline 10 & World Scientific Publishing Co. & 67 & 129 \\
\hline 11 & Allen Press & 112 & 120 \\
\hline 12 & S. Karger AG & 71 & 83 \\
\hline 13 & Marcel Dekker, Inc. & 80 & 80 \\
\hline 14 & $\begin{array}{l}\text { British Medical Journals Publishing (BMJ } \\
\text { Publishing) }\end{array}$ & 25 & 29 \\
\hline 15 & Humana Press & $\mathbf{4 , 6 6 7}$ & $\mathbf{8 , 0 7 7}$ \\
\hline & Total Number of Electronic Journals & \\
\hline
\end{tabular}

Table 1: Ranked List of For-Profit Publishers 


\begin{tabular}{|c|l|c|c|}
\hline \multirow{2}{*}{ Rank } & \multicolumn{1}{|c|}{ Not-for-Profit Publishers } & \multicolumn{2}{|c|}{ Number of E-Journals } \\
\cline { 2 - 4 } & & In 2003 & In 2007 \\
\hline 1 & Cambridge University Press & 157 & 256 \\
\hline 2 & Oxford University Press & 180 & 207 \\
\hline 3 & $\begin{array}{l}\text { IEEE (Institute of Electrical and Electronic } \\
\text { Engineering) }\end{array}$ & 120 & 128 \\
\hline 4 & Institute Of Physics Publishing (IOP) & 40 & 53 \\
\hline 5 & American Psychological Association & 45 & 51 \\
\hline 6 & University of Chicago Press & 30 & 49 \\
\hline 7 & $\begin{array}{l}\text { ACM Press (Association for Computing } \\
\text { Machinery) }\end{array}$ & 30 & 47 \\
\hline 8 & American Chemical Society & 35 & 36 \\
\hline 9 & Royal Society of Chemistry & 35 & 36 \\
\hline 10 & Annual Reviews & 29 & 32 \\
\hline 11 & MIT Press & 30 & 32 \\
\hline 12 & American Society of Civil Engineering & 29 & 30 \\
\hline 13 & $\begin{array}{l}\text { American Society of Mechanical } \\
\text { Engineering }\end{array}$ & 22 & 22 \\
\hline 14 & American Geophysical Union (AGU) & $\mathbf{8 1 4}$ & 18 \\
\hline 15 & Royal Society of Medicine & & 16 \\
\hline & Total Number of Electronic Journals & \\
\hline & & & \\
\hline
\end{tabular}

Table 2: Ranked List of Not-for-Profit Publishers

While the complete lists were used for initial studies, for the detailed study, the research was limited to six publishers, the top three from each category. Elsevier, Springer, and Taylor \& Francis Ltd., formed for-profit category; and Cambridge University Press, Oxford University Press and IEEE formed not-for-profit category. 
Criteria for selecting publishers was the number of electronic journals published by them in 2007. The purpose of the study was analytical study of the archiving policies of different publishers for electronic journals.

\section{Commercial Publishers' Archiving Policies}

\section{Elsevier}

The need to provide for permanent digital archiving has been evident to libraries and to Elsevier for several years. In 1999 Elsevier Science made a public commitment to ensure digital archiving with a trusted repository and made this part of its license with library customers including KB (Koninklijke Bibliotheek) [28].

Elsevier's policy for electronic journal archiving is addressed in its agreements with libraries. One such example is the agreement between Elsevier and the KB. The KB is the National Library of the Netherlands. The Library was founded in 1798. The KB is an autonomous administrative body financed by the Dutch Ministry of Education, Culture \& Science. The KB's mission statement is to provide universal access to the knowledge and culture of the past and present by providing high quality services for research, study and cultural enrichment. Elsevier Science is also headquartered in Amsterdam, The Netherlands [29].

Elsevier started discussions with the KB in 1995 with the introduction of Elsevier Electronic Subscriptions and signed an agreement with the KB in 1996 to deposit ecopies of all Elsevier Science journals with a Dutch imprint. This was initially 270 journals and currently is 351 . By autumn 2000 Elsevier also determined that it would be desirable to go a step further and deposit the e-journals on a current basis with a trusted repository. While there have been (and continue to be) discussions with libraries in many parts of the world, the KB was the natural partner, as it is the home national library for Elsevier and a clear leader in digital preservation development and discussions started in October, 2000. At the same time Elsevier also started working on an archival project with Yale University Library, partnering with them in 2001 with funding from the Mellon Foundation. This research project, which involved close co-operation with the KB, reconfirmed certain key archival principles, including the need to focus on content 
preservation (rather than look and feel) and to adopt the OAIS standards for preservation systems. That project was concluded in March, 2002 [30].

Then, Elsevier and the KB made a new agreement for electronic archiving in August 2002 for ten years. This means the library will receive digital copies of all Elsevier journals made available on its web platform, ScienceDirect, which had approximately 1,500 journals covering all areas of science, technology and medicine, and exceeding $7 \mathrm{~TB}$ of data at the time of this agreement in 2002. Elsevier was the first publisher which made an agreement regarding electronic archiving with the $\mathrm{KB}$, so this agreement became a base agreement with other publishers. This base or generic standard

agreement is available at: http://www.crl.edu/content/DigArc/KBElsevierArchivingAgreement09200411.pdf. [31]. Appendix A shows the generic standard agreement between the KB and any publisher in general. To give an example of the exact agreement, listed below are the terms of 2 and 3 of real agreement between Elsevier and the KB:

"2. Elsevier will deliver within three months after a request from the KB (but not later than the end of 2002) in the format noted in Annex 1.1 hereto the Elsevier Journal material published and made available on the ScienceDirect platform (http://www.sciencedirect.com) ("ScienceDirect") at that time (the "Initial Delivery"). The Initial Delivery will also include existing backfiles of the Elsevier Journals available on ScienceDirect."

"3. The KB will after receipt of the Initial Delivery begin loading those materials into its digital archive more fully described on Annex 1.2 hereto (the "KB Archive"). The KB anticipates that it will finish the loading of the Initial Delivery within three months of receipt and not later than March 31, 2003."

It may be noted that the generic standard agreement is made for three years but in the case of Elsevier, it has an initial 10 year term, with five year renewal terms.

\section{Springer (includes Kluwer Academic Publishers)}

In 2003, the KB signed an agreement on long-term digital archiving of the electronic publications of Kluwer Online. Under the terms of this agreement, Koninklijke 
Bibliotheek will receive digital copies of all Kluwer journals and books made available on its web platform, Kluwer Online. Kluwer merged with Springer in September 2003 and its journals became available through Springer. Springer and the KB have also made an agreement on long-term archiving of online publications. The National Library of the Netherlands will receive 100,000 articles per year from 1,200 journals. Also 1.5 million articles from Springer's historical online archive and 2,000 e-Books published annually from SpringerLink for its electronic depot [32]. The agreement between Springer and the $\mathrm{KB}$ was based on the basic/ generic standard agreement, given in the Appendix.

\section{Taylor \& Francis}

In November 2004, the KB signed an agreement on long term digital archiving of all electronic journals of the Taylor \& Francis Group. Under the terms of this agreement the KB will receive digital copies of all journals made available on the online platform of Taylor \& Francis [33]. The agreement between Taylor \& Francis and the KB was made base on the basic/generic standard agreement (as in the Appendix).

\section{Academic and Society Publishers' Archiving Policies \\ Cambridge University Press}

In 2003 a press release from the University of Cambridge announced a joint project between the Cambridge University Library and the Massachusetts Institute of Technology (MIT) Libraries to establish a digital repository based on the DSpace software. The press release says that the Cambridge system - to be known as DSpace@Cambridge, will have two main roles.

Firstly, it "has the ability to capture, index, store, disseminate and preserve digital material created by the academic community, including scholarly articles and preprints, theses, technical reports, archives and other textual material, together with different formats such as multimedia clips, interactive teaching programmes, datasets and databases. Secondly, it will provide a home for the increasing amount of material that is being digitized from the University Library's collections" [34]. 
In addition, Cambridge University Press has been involving in the establishment of a research archive of educational case studies drawing on the work of participants from around the world in the 'Cambridge Conferences', on educational evaluation which have been taking place since 1972 .

The archive will be constructed using the D-Space digital repository and the Sakai Collaboration and Learning Environment (CLE) hosted at the University of Cambridge Centre for Applied Research in Educational Technologies (CARET) with user access via a suite of 'Semantic Web' applications. This will allow not only resource description and discovery, but will also provide a basis for the resources to be presented to the widest possible range of users through a range of web interfaces.

The intention of the project is not only to develop an archive of context-rich and significant case studies, but also to model a replicable process by which other archives could be developed in fields where complex, case-based data need to be securely archived but also retrieved, extended and combined in innovative ways.

\section{Oxford University Press}

Oxford Journals, a Division of Oxford University Press, publishes 207 journals covering a broad range of subject areas, two-thirds of which are published in collaboration with learned societies and other international organizations. In 2006 -Oxford Journals, has signed a key archiving agreement with Portico, an electronic archiving service launched in 2005 with funding from JSTOR (Journal Storage), The Andrew W. Mellon Foundation, Ithaka and The Library of Congress [35].

Portico is a new, not-for-profit electronic archiving service established in order to address the scholarly community's critical and urgent need for a robust, reliable means to preserve electronic scholarly journals. Portico recognises that while access to e-journal literature today may not be a concern, librarians and their constituents do need to have assurance of future access, a theme echoed in the Urgent Action statement noted earlier [36]. To address this need, all libraries supporting the Portico archive have campus-wide access to archived content when specific trigger events occur, and when titles are no longer available from the publisher or other source. Trigger events include when a 
publisher ceases operations; or ceases to publish a title; or no longer offers back issues; or suffers catastrophic and sustained failure of a publisher's delivery platform [37].

In addition to these trigger events, both publishers and libraries have recognised that in some cases, even after a library has terminated a licence to an electronic resource, it may be necessary for that library to continue to have ongoing access. This is commonly known as 'perpetual access' or post-cancellation access. A publisher may choose to extend perpetual access to a library and that access can be provided through the Portico archive, if the publisher desires. In addition, select librarians at participating libraries are granted password-controlled access to the archive for verification purposes. This verification access, which is granted to the entire archive, is not intended to be used as a replacement for commercial document delivery services or to fulfill inter-library loan requests. Finally, all publishers participating in the archive have full access to their own content and any content for which a trigger event prevails [38].

The Portico archive relies upon the co-operative participation of both publishers and libraries. To participate in Portico, a publisher:

1. signs a non-exclusive archiving licence that gives Portico the right to ingest, normalise, archive, and migrate the publisher's content

2. indicates whether Portico will serve as a perpetual access mechanism

3. supplies electronic journal source files in a timely way, and

4. makes an annual financial contribution.

To participate in the Portico archive, a library:

1. signs an archiving licence agreement

2. makes an annual support payment, and

3. provides IP or other relevant information for user authentication purposes [39].

Agreement with Portico is the third major archiving agreement that Oxford Journals is participating in, as part of their commitment to ensure long term accessibility to all journals content. 
In 2004, Oxford Journals signed an archiving agreement with the KB and in 2005 became a member of the LOCKSS (Lots of Copies Keep Stuff Safe) preservation initiative from Stanford University. By signing this new agreement with Portico, Oxford Journals now have an enhanced ability to offer perpetual access, back-up archiving, and access facilities for all participating journals.

Oxford Journals is currently participating in two additional initiatives, all in development: (1) CLOCKSS (Controlled LOCKSS) is a two year pilot from the LOCKSS initiative, to investigate a failsafe repository to ensure delivery of content in the event of a disaster; and (2) the Library of Congress Pilot Testing of Voluntary Copyright Deposits project.

\section{IEEE (Institute of Electrical and Electronics Engineers)}

The MTT Society (Microwave Theory and Techniques Society, MTT-S) has started a major effort to archive 50 years of MTT transactions, and all other major publications including the IEEE Microwave and Wireless Components Letters, the International Microwave Symposium (IMS) Digest and the Radio Frequency Integrated Circuits (RFIC) Symposium Digest. The initial collection, with well over 50,000 pages, filled about 18 CDROMs. Every year, the MTT Society produces a new CDROM containing the new papers published in the above publications. The format features word searches using the Adobe Acrobat Reader and a special index based on abstracts. A single CDROM index is also updated and made available to the MTT-S members to allow abstracts and articles to be searched over the entire collection of CDROMs [40].

All IEEE online publications delivered through the IEEEXplore. Access to tables of contents of IEEE transactions, journals, magazines, conference proceedings and standards is free to all users. In order to access to full text institutions need to register and pay subscription fees. Upon termination of an online subscription, the subscribing institution (Licensee) may retain the archival rights for the content received during their subscription period. 


\section{Discussion and Conclusion}

The long-term archiving of electronic journals is one of the important challenges for libraries and publishers. While libraries and publishers have had stable roles for centuries (publishers produced information; libraries provided access to this information), the evolution of the information technology has disrupted this critical role for libraries. Librarians currently face many issues and concerns for archiving electronic journals, such as differences between digital and print media, rapid obsolescence of digital technology, shift in the responsibility of archiving to publishers, legal issues such as copyright and intellectual property rights, selection, and many more. On the other side, scientific publishers have become aware of the issues and are rising to the challenge by implementing long-term preservation policies [41].

This study focused on the archiving policies of six leading for-profit and not-forprofit publishers. The publishers were identified and ranked by their number of electronic journals in 2007. The number of electronic journals in 2003 is also seen in Tables 1 and 2. The author had carried out a study on the economics of the same publishers in 2003 and had access to information regarding the number of the electronic journals in 2003 [42]. Therefore a comparison is made between the numbers of electronic journals among publishers.

As of February 2007, the data show that in general the publishers have increased the number of electronic journals since 2003. Elsevier, topping the list since 2003, is the biggest publisher of scholarly electronic journals with 2,220 journals in 2007. The number of electronic journals published by Springer increased from 436 in 2003 to 1,616 in 2007. One of the reasons is the merger of Kluwer with Springer at the end of 2003. Kluwer was considered as an independent publisher in the 2003 study.

Not-for-profit publishers also increased their numbers of electronic journals since 2003. Oxford University Press led the list in 2003, but Cambridge University Press became the biggest not-for-profit publisher in 2007. As of February 2007, Tables 1 and 2 also show that the number of electronic journals published by for-profit publishers is significantly higher than not-for-profit publishers. For example, in 2007 the smallest forprofit publisher in this study (Taylor \& Francis) publishes five times more than the 
largest not-for-profit publisher (Cambridge University Press). A comparison between the total number of journals shows that the total number of journals published by top fifteen for-profit publishers increased 1.7 percent and the total number of journals published by top fifteen not-for-profit publishers increased 1.2 percent since 2003.

This study showed that while commercial publishers are dominant in the publishing of scholarly electronic journals, they have also taken the responsibility of archiving more seriously than not-for-profit publishers. They have systematically tried to have a long-term preservation for their journals. The National Library of the Netherlands or Koninklijke Bibliotheek (KB) has become the main library which all three for-profit publishers made an agreement with. Elsevier was the first publisher to have an agreement with the KB.

After the agreement with Elsevier, the KB concluded similar agreements with Kluwer Academic Publishers (2003), BioMed Central (2003), Blackwell (2004), Oxford University Press (2004), Taylor \& Francis (2004), Sage (2005), Springer (2005), and Brill Academic Publishers (2005). All KB agreements dictate that the KB will preserve what the publisher sends to the library. The archived content is exactly the same as the published content. This coverage may change as publications become more complex and include multimedia and dynamic content. For now, however, the KB's policy is to preserve "as is." As a part of the agreements, the KB provides on-site access to the journals on a current basis to all on-site, authorized library users. The agreement covers new publications, as well as digitized backfiles. In addition, should there be a catastrophic disaster such that the publisher is inoperable for a long period of time, the $\mathrm{KB}$ would be part of the interim service system [43].

The agreements between the KB and leading publishers of scholarly electronic journals are significant developments in keeping digital archives available in perpetuity. The relationship evokes the traditional role of the library, particularly of national libraries, in undertaking preservation responsibility, while also asserting the commercial role of the publisher.

Among the three top not-for-profit publishers, only Oxford University Press made an agreement with the KB. The University of Cambridge is working with the Massachusetts Institute of Technology (MIT) Libraries to establish a digital repository 
based on the DSpace software. IEEE is following its own archiving policy and prepared the electronic material on CDs. Though the number of electronic journals published by IEEE and not-for-profit publishers in general is less than for-profit publishers, CD-ROMs are not be considered adequate storage for long-term preservation. The CD-ROMs are digital media with a short lifecycle; therefore, IEEE needs to reconsider its archiving policy.

Finally, despite these agreements and developments, the field of digital archiving is still in its infancy, and much work needs to be accomplished to achieve a secure and permanent archiving of electronic journals. However, the successful agreements between the $\mathrm{KB}$ and the leading for-profit publishers could be used as a model for other publishers, especially for not-for-profit publishers and other publishers around the world.

Acknowledgement: The author gratefully acknowledges Professor Connie Foster, Editor,

Serials Review, Head, Department of Library Technical Services, Western Kentucky University Libraries, for help in editing this paper and Ms. Karen Hunter, Elsevier Senior Vice President, for providing information about the Generic Standard Agreement.

\section{Notes}

1. John Colvin and Judith Keene, "Supporting Undergraduate Learning through the Collaborative Promotion of E-Journals by Library and Academic Departments," Information Research 9, no. 2 (January 2004).

2. Golnessa Galyani Moghaddam, "Use of Scholarly Electronic Journals: A Case Study in India," submitted to Libri: International Journal of Libraries and Information Services (under Review 2007).

3. Richard Poynder, "Elephants and Dung-Trucks,"Information Today 20, no. 8 (2003), http://www.dspace.dial.pipex.com/town/parade/df04/elephants_and_dung.htm (accessed July 15, 2006).

4. Johan F. Steenbakkers, "Digital Archiving in the Twenty-First Century: Practice at the National Library of the Netherlands," Library Trends (Summer 2005).

5. Hall R. Varian, "The Future of Electronic Journals: Some Speculations about the Evolution of Academic Electronic Technology Conference: Conference organized 
by the Andrew W. Foundation atEmoryUniversity,Atlanta,April 24-25, 1997, http://arl.cni.org/scomm/scat/index.html (accessed January 15, 2007).

6. Ziming Liu, "Reading Behavior in the Digital Environment: Changes in Reading Behavior Over the Past Ten Years," Journal of Documentation 61, no. 6 (2005): 700-712.

7. Carol Tenopir, "Inundated with Data," (September 2005) http://www.libraryjournal.com (accessed December 15, 2006).

8. Steenbakkers, "Digital Archiving," Library Trends (Summer, 2005).

9. N.V. Sathyanarayana, "Electronic Journals: Access and Delivery Models," Information Studies 6, no. 2 (April 2000).

10. David Bearman, "Reality and Chimeras in the Preservation of Electronic Records," D-Lib Magazine (April, 1999) 5 (4) http://www.dlib.org/dlib/april99/bearman/04bearman.html (accessed December 30, 2006).

11. PADI (Preserving Access to Digital Information), Standard (2001) http://www.nla.gov.au/padi/topics/43.html [2001] (accessed December 11, 2006).

12. Helen Hockx-Yu, "Digital Preservation in the Context of Institutional Repositories,"

http://www.eprints.rclis.org/archive/00007351/01/DPinIRs_Final.pdf (accessed September 30, 2006).

13. Dale Flecker, "Preserving Scholarly E-Journals," D-Lib Magazine (September, 2001) 7 (9) http://www.dlib.org/dlib/september01/flecker/09flecker.html (accessed September 20, 2006).

14. Adrienne Muir, "Preservation, Access and Intellectual Property Rights Challenges for Libraries in the Digital Environment," Institute for Public Policy Research (ippr) (June 2006).

15. Mary Feeney, "Towards a National Strategy for Archiving Digital Materials,"Alexandria 11, no. 2 (1999): 107-122.

16. "Urgent Action Needed to Preserve Scholarly Electronic Journals," edited by Donald J. Waters, The Andrew W. Mellon Foundation, (October 2005): 15.

17. Ibid.

18. Neil McLean, "The Archiving of Electronic Scholarly Information: Executive Summary," (1998). http://www.unison.nsw.edu.au/ (accessed January 4, 2007). 
19. Emma Poole, "Digital Knowledge for All, but What about for Ever?" (June, 2005), http://www.mla.gov.uk/resources/assets//M//mla_dpc_survey_pdf_7486.pdf (accessed January 5, 2007).

20. Catherine Ayre and Adrienne Muir, "Right to Preserve? Copyright and Licensing for Digital Preservation Project Final Report,"(Loughborough: Loughborough University, 2004), http://www.lboro.ac.uk/departments/dils/disresearch/CLDP/Project_reports.htm (accessed January 10, 2007).

21. Robert P. Dellavalle et al., "Going, Going, Gone: Lost Internet References," Science 302, no. 5646 (October 31, 2003): 787-788.

22. Michael Bugeja and Daniela V. Dimitrova, "The Half-Life Phenomenon: Eroding Citations in Journals," The Serials Librarian 49, no. 3 (2005): 117.

23. Eileen Fenton, "Preserving Electronic Scholarly Journals: Portico," Ariadne (April, 2006): 17, http://www.ariadne.ac.uk/issue47/fenton/intro.html (accessed January 11, 2007).

24. "Electronic Research Resources" survey of 7,403 faculty conducted in 2003 by Odyssey, a market research firm, on behalf of Ithaka (unpublished).

25. Mark Young and Martha Kyrillidou, ARL Statistics 2003-04, Association of Research Libraries, (Washington, DC: The Association, 2005).

26. Fenton, "Preserving," 47.

27. Kate O'Donohue, “The Accessing and Archiving of Electronic Journals: Challenges and Implications within the Library World "The Serials Librarian 49, no. 1-2 (2005): 35-87.

28. http://www.elsevier.nl/ (Accessed January 05, 2007).

29. "National Library of the Netherlands and Elsevier Science Make Digital Preservation History" (2002). http://www.kb.nl/hrd/dd/dd_links_en_publicaties/publicaties/eskb_pressrelease7_ 20aug02_def.pdf (accessed January 12, 2007).

30. http://www.elsevier.com/wps/find/subject_area_browse.cws_home (accessed January 13, 2007).

31. "BASE CONTRACT 092004: Archiving Agreement", http://www.crl.edu/content/DigArc/KBElsevierArchivingAgreement09200411.pd f (accessed January 14, 2007). 
32. http://www.ringgold.com/directory/cfm/ringgold_dir.cfm?ob_id=1318_and_br_id $=2($ accessed January 15,2007$)$.

33. http://www.tandf.co.uk/journals/ (accessed August 11, 2006).

34. http://www.lib.cam.ac.uk/dspace/ (accessed August 29, 2006).

35. http://www.digitalpreservation.gov/ (accessed August 9, 2006).

36. "Urgent Action," 15.

37. Fenton "Preserving," 47.

38. Ibid.

39. Ibid.

40. http://www.ieee.org/onlinepubs/ (accessed June 22, 2006). 41. Steenbakkers, "Digital Archiving," Library Trends (Summer, 2005).

41. Galyani Moghaddam, Golnessa. "Scholarly Electronic Journal Publishing: A Study Comparing Commercial and Nonprofit/University Publishers," The Serials Librarian 51, no. 3/4 (2007): 165-183.

42. Robin Dale, "The Center for Research Libraries: Archive Profile of the National Library of the Netherlands," http://www.crl.edu/content/DigArc/DigArc2/KBprofile.pdf (accessed January 8, 2007). 


\section{Appendix A}

\section{Basic/Generic Standard Agreement}

1. AGREEMENT, dated effectively as of datum (the "Agreement"), between the Koninklijke Bibliotheek, the National Library of the Netherlands operating as an autonomous administrative body of the Ministry of Education, Culture \& Science with business address at Prins Willem-Alexanderhof 5, the Hague (the "KB") and Publisher, address

2. Publisher will deliver within $\mathbf{x x x x}$ months after a request from the KB (but not later than $\mathbf{x x x x}$ ) in the format noted in this agreement hereto the Publisher Publications published and made available on the Publisher online platform (www.xxxx.xxx) at that time (the "Initial Delivery"). The Initial Delivery will also include existing backfiles of the Publisher Publications.

3. After receipt of the Initial Delivery the $\mathrm{KB}$ will begin loading those materials into its digital archive (the "KB Archive"). The KB anticipates that it will finish the loading of the Initial Delivery within $\mathbf{x x x x}$ months of receipt and not later than datum.

4. After the Initial Delivery, Publisher will not less often than monthly deliver Publisher Publications content made available on Publisher online not previously delivered, including any new backfile material (the "Periodic Deliveries"). The Periodic Deliveries shall be in the format noted in this agreement hereto or as may be hereinafter changed by Publisher upon notice to the KB. Prior to implementing any significant changes, Publisher will consult with the KB to ensure that the new format can be accommodated by the KB. After both the Initial Delivery and the first three Periodic Deliveries have been loaded, the KB will load the materials from the Periodic Deliveries into the KB Archive within one month of delivery.

5. Publisher and the KB understand that on occasion modifications to the content of an article in the KB Archive, after it has been delivered by Publisher, to the KB may be reasonably required. While individual cases will be handled as they occur, it is agreed that nothing will be permanently deleted from the archive, although Publisher may request that an article be "sequestered" by removing it from public access and substituting a notice of its unavailability. This would only be done in very extraordinary circumstances, such as under court order, serious copyright violation or where an article is found to have information that is faulty and of great danger to human health, if followed.

6. Use by the $\mathrm{KB}$ of the Publisher Publications delivered hereunder will be governed with respect to the KB Archive by the license provisions noted below in Article II. No other rights are granted by Publisher and are hereby reserved. Without limiting the generality of the foregoing, the materials provided hereunder by Publisher (or copies thereof) may not be lent out or otherwise distributed. 
There will be no fees charged for the licenses or services provided by the parties to each other unless specifically noted herein.

7. The KB will maintain the integrity of the Publisher Publications content delivered and used as noted hereunder and commits to the long-term and perpetual storage and maintenance of these materials, as further described below in Article III.

8. The parties will co-operate with respect to other joint projects in the field of archiving Publisher Publications including without limitation the possibility that the KB would serve as a host for former Publisher online customers who wish to have long-term access to certain content as authorised by Publisher. In such a case, the parties will negotiate with respect to developing appropriate access control mechanisms for such customers. The parties anticipate that the KB may charge such customers a fee for such services.

9. The KB will also provide emergency host access in the event of a catastrophic occurrence to Publisher's online services such as Publisher online, upon notice from Publisher that such services have become unavailable and will not be available for such time as would materially impact Publisher online customer access. Access under such extraordinary circumstances will include access by remote users as well as by Publisher staff and contractors, but authentication of users will not be required, and the arrangement will end when Publisher indicates it can provide normal services again. In such event Publisher agrees to compensate the $\mathrm{KB}$ for direct costs such as extra telecommunication charges and personnel costs. In the event that the $\mathrm{KB}$ is asked to provide these services for longer than six weeks, the parties will negotiate in good faith a reasonable rate of compensation for the $\mathrm{KB}$ in connection with its additional costs and the KB's costs with respect to its employees required to help maintain and provide these additional services.

10. Publisher will use all reasonable efforts to ensure that the KB may maintain the materials delivered to it by Publisher for the Digital Archive for Publisher Publications that cease to be owned or published under license by Publisher in the future, through arrangements with the new owner.

11. Usage of the Publisher Publications archived by the KB will be limited as follows:

- information about the Publisher Publications may be included in the KB's online public catalogue or in the National Bibliography;

- on-site use only (i.e. within the premises of the KB's physical facilities open to the public) for those persons authorised by the $\mathrm{KB}$ as $\mathrm{KB}$ passholders;

- on-site or remote access by $\mathrm{KB}$ staff authorised by the $\mathrm{KB}$ to work with the KB Archive; and 
- use as a source for print or fax copies of articles for interlibrary loan within the Netherlands (sending or transferring the electronic file by any means is not allowed).

12. All public users of the Publisher Publications will be informed by the KB that only on-site usage is permitted. The KB will not delete or modify any proprietary notices included in the Publisher Publications and will ensure that such notices can be viewed by users.

13. The KB will provide or provide for the permanent storage and maintenance of the Publisher Publications delivered pursuant to this Agreement and their preservation in a form that will provide security as to data integrity, usability and access control. The KB will employ appropriate technical solutions to adapt to changes in storage or access technology and to otherwise ensure the continued availability (in accordance with this Agreement) of the Publisher Publications. The KB accepts and understands that the best standards and procedures for the storage, manipulation and access of digital materials are likely to evolve over time and that it will avail itself of the latest technologies in cooperation with Publisher. In making this commitment, the KB is explicitly assuming the role of an official, non-exclusive archival agent for Publisher (but limited as noted above under 1.5) for at least the duration of this Agreement and its extensions, and to make reasonable efforts to do so in perpetuity.

14. The term of this Agreement will be three (3) years, renewable for additional three (3) year terms, unless a notice of expiration has been given. The parties must give notice six months before the expiration of any subsequent terms that they do not intend to renew. 